\title{
Biological Control Potential of Streptomyces sp. AR10 Producing Albocycline Isolated from Soil around Ant Nest
}

\author{
Tatsuya Ohike ${ }^{1}$, Tetsuya Matsukawa ${ }^{1}$, Masahiro Okanami ${ }^{1}$, Shin'ichiro Kajiyama ${ }^{1} \&$ Takashi Ano $^{1}$ \\ ${ }^{1}$ Graduate School of Biology-Oriented Science and Technology, Kindai University, Wakayama, Japan \\ Correspondence: Tatsuya Ohike, Graduate School of Biology-Oriented Science and Technology, Kindai \\ University, 930 Nishimitani, Kinokawa City, Wakayama 649-6493, Japan. E-mail: \\ 1544710254e@waka.kindai.ac.jp
}

Received: December 19, 2017

Accepted: January 18, 2018 Online Published: February 15, 2018

doi:10.5539/jas.v10n3p54

URL: https://doi.org/10.5539/jas.v10n3p54

\begin{abstract}
Fifty actinomycetes were isolated from fifteen soil samples and were screened for their antagonism against fungal plant pathogens by dual culture assay, and one of the strain named AR10 was shown to be most effective in suppression of growth of plant pathogen. An antifungal compound of AR10 was extracted, and purified by TLC and HPLC. As a result of NMR and LC-MS analysis, the antifungal compound was identified as albocycline. AR10 suppressed Rhizoctonia damping-off of cucumber in infection control assay. The 16S rDNA sequence of AR10 shows high sequence similarity to those of genus Streptomyces, and the closest similarity was found in the sequence of $S$. lanatus $\mathrm{NBRC} 12787^{\mathrm{T}}$ with $98.7 \%$ similarity. However, the production of albocycline in Streptomyces closely related to AR10 in the phylogenetic tree has not been reported. Our finding suggests that AR10 can be a candidate for biological control agents.
\end{abstract}

Keywords: biological control, actinomycetes, albocycline, antifungal activity, Rhizoctonia solani

\section{Introduction}

Food shortage is one of the most critical problems in the world, and to solve this problem, it is necessary to improve and protect the crop production (FAO, 2012). Phytopathogens affect the growths and productivities of crop plants, and there are wide varieties of phytopathogens in the world. For example, Rhizoctonia solani is a plant pathogen which infects crops such as rice, tomato and cucumber, and the incidence of disease caused by this pathogen is rising annually (Jaiswal, Elad, Graber, \& Frenkel, 2007; Chuping, Xuehui, Huafei, Xiaoyu, \& Zhiyi, 2014; Chellemi, 2002). Fusarium oxysporum also causes wilt disease in more than 100 kinds of plants such as banana, melon, and tomato (Chikh-Rouhou et al., 2013; Ploetz, 2006; Brzezinska, Jankiewicz, \& Walczak, 2013). To control both pathogens and hence the diseases that caused, many chemical fungicides have been developed and used. However, excessive use of chemical fungicides has some problems, such as environmental pollution, deteriorating human health, and development of drug-resistant pathogens/insects (Staub \& Sozzi, 1984; Ando, 1991; Clevo \& Clem, 2001). Therefore, biological control agents which reduce the negative impacts on the environment and ecosystems have attracted much attention as an alternative to the use of chemical fungicide.

More than $70 \%$ of naturally occurring antibiotics have been isolated from different genus of actinomycetes (Prabavathy, Mathivanan, \& Murugesan, 2006; Wang et al., 2013). Streptomycetes are known to produce much more antibiotics than actinomycetes in other genera, and are thought to have strong biocontrol activity against various phytopathogens. They also secrete extracellular hydrolytic enzymes such as chitinases and glucanases, which can degrade components in the cell walls of plant pathogens (Castillo et al., 2016; Sakdapetsiri et al., 2016). However, in spite of these advantages, reports of biological control application by actinomycetes are less than those from other bacteria such as Pseudomonas or Bacillus.

Haeder et al. (2009) reported that leaf-cutting ants were using actinomycetes to control its own nest environment. Leaf-cutting ants live in symbiosis with fungi of the genus Leucoagaricus, and the symbiotic fungi serve as a major food source for the ants, and this symbiotic relationship is threatened by another pathogenic fungi. Leaf-cutting ants use actinomycetes to protect the symbiotic fungi from infections by pathogenic fungi (Haeder et al., 2009; Oh, Poulsen, Currie, \& Clard, 2009; Poulsen et al., 2003). This symbiotic relationship of leaf cutting 
ants with actinomycetes are considered to be consistent with the concept of biological control application, and research on biological control using actinomycetes are considered to contribute to sustainable agriculture.

In this study, actinomycetes with strong antifungal activity against plant pathogens were isolated as candidates for biological control strain from the soil around ant nest. These actinomycetes were tested for infection control test against plant pathogens, and a strain with the strongest antifungal activity was identified and characterized.

\section{Method}

\subsection{Microorganisms}

Ant nest soil samples were obtained from different places in the Kinki area of Japan. Among the bacteria isolated from the samples, fifty strains of actinomycetes were selected, and incubated on albumin medium containing $0.025 \%$ egg albumin, $0.1 \%$ glucose, $0.05 \% \mathrm{~K}_{2} \mathrm{HPO}_{4}, 0.02 \% \mathrm{MgSO}_{4} \cdot 7 \mathrm{H}_{2} \mathrm{O}, 0.0004 \% \mathrm{Fe}_{2}\left(\mathrm{SO}_{4}\right)_{3}, 1.5 \%$ agar, and $50 \mathrm{mg} / \mathrm{L}$ cycloheximide at $24{ }^{\circ} \mathrm{C}$ for 12 days. Isolated colonies of actinomycetes were preserved and maintained on PDA (potato dextrose broth agar; Difco) medium at $24{ }^{\circ} \mathrm{C}$. The plant pathogenic fungi used were laboratory stock, which had been obtained from the NARO Genebank [Bipolaris oryzae (MAFF 305382), Colletotrichum echinochloae (MAFF 305460), Colletotrichum orbiculare (MAFF 306685), Fusarium oxysporum (MAFF 103038), Fusarium solani (MAFF 235170), Monilinia fructigena (MAFF 305640), Phytophthora infestans (MAFF 236324), and Rhizoctonia solani (MAFF 235846)]. They were incubated on PDA medium at $24^{\circ} \mathrm{C}$ for 7 days before use.

\subsection{Antifungal Activity of Actinomycetes}

Antifungal activity of isolated fifty actinomycetes against plant pathogens were evaluated by dual culture assay. A single agar plug of $0.7-\mathrm{cm}$ diameter, cut from the edge of actively growing fungal mycelium, was placed on the perimeters of the PDA plate at a distance of $1.5 \mathrm{~cm}$, and then an actinomycete was inoculated on the opposite of the fungal mycelium. Plates were incubated for 3-4 days at $24{ }^{\circ} \mathrm{C}$. The antifungal activity of the compound purified by HPLC was assayed against $R$. solani by disk diffusion test. The paper disks were placed at PDA plate and treated with $200 \mu \mathrm{g}$ of purified compound.

\subsection{Extraction of Antifungal Compound}

The AR10 was cultivated on PDA medium at $24{ }^{\circ} \mathrm{C}$. After 7 days of incubation, the colony was transferred into the $800 \mathrm{~mL}$ PDB medium and incubated at 1,000 rpm for 10 days. After incubation, $800 \mathrm{~mL}$ of ethyl acetate was added to the culture solution for extraction. The extraction was repeated three times, and the resulting organic layers were combined (ca. $2.4 \mathrm{~L}$ ) and evaporated. The dried residues were used for TLC analysis.

\subsection{TLC Analysis}

Crude extracts were subjected to TLC (Silica gel $60 \mathrm{~F}_{254}$; Merck Milipore) using toluene: ethyl acetate: acetic acid (16:4:1) as a solvent and observed under UV light at $254 \mathrm{~nm}$. After TLC analysis, TLC plates were cut into 5 fractions and used for bioautography test. The cut TLC plates were placed on the perimeters of the PDA plate at a distance of $1.5 \mathrm{~cm}$, and then $R$. solani was inoculated on the opposite of the TLC plate. PDA plates were incubated for 3-4 days at $24^{\circ} \mathrm{C}$.

\subsection{Identification and Characterization of Antifungal Compound}

Crude extract was applied to preparative TLC under the same condition described above (section 2.4). TLC fractions containing antifungal compounds were dissolved in methanol, and used for HPLC separation.

HPLC-UV analysis was performed using a JASCO LC-2000 system equipped with an Inertsil ODS-3 column (4.6 mm i.d. by $150 \mathrm{~mm}$; GL Science) at a flow rate of $1.0 \mathrm{~mL} / \mathrm{min}$. For separation, a mixture of $50 \%$ acetonitrile/water were used as mobile phase, and the antifungal compound was detected by absorbance at 254 $\mathrm{nm}$.

LC-MS analysis was performed using a QTrap (AB SCIEX) system with an Inertsil ODS-3 column (2.1 mm i.d. by $150 \mathrm{~mm}$; GL Science) at a flow rate of $0.2 \mathrm{~mL} / \mathrm{min}$. For separation, distilled water and acetonitrile were used as mobile phase, and a linear gradient of $30-80 \%$ acetonitrile was applied. The mass spectrometer analysis was performed using ESI+ mode, using $[\mathrm{M}+\mathrm{H}]^{+}=309.5 \mathrm{amu}$ as the qualifier ion.

Chemical structure of the purified antifungal compound was determined by NMR analysis. The purified antifungal compound was dissolved in Chloroform-d $\left(\mathrm{CDCl}_{3}\right)$ and then subjected to spectral analysis. NMR spectra were recorded on a Anova-600 (BRUKER Bio Spin) operating at $600 \mathrm{MHz}$ and the data obtained were the following: 
${ }^{1} \mathrm{H}-\mathrm{NMR} \delta: 0.84(3 \mathrm{H}, d, J=6.9 \mathrm{~Hz}, 12-\mathrm{Me}), 1.13(1 \mathrm{H}, m, \mathrm{H}-11), 1.17$ (3H, $\left.d, J=6.4 \mathrm{~Hz}, 13-\mathrm{Me}\right), 1.19$ (1H, $m$, H-11'), 1.40 (1H, m, H-12), 1.49 (3H, $s, 4-\mathrm{Me}), 1.60$ (3H, $s, 8-\mathrm{Me}), 1.80$ (1H, $m, \mathrm{H}-10), 2.10$ (1H, $m, \mathrm{H}-10$ '), $3.26(3 \mathrm{H}, s, 7-\mathrm{OMe}), 4.03(1 \mathrm{H}, d, J=6.2 \mathrm{~Hz}, \mathrm{H}-7), 4.51(1 \mathrm{H}, d q, J=6.4,8.5 \mathrm{~Hz}, \mathrm{H}-13), 5.24(1 \mathrm{H}, t, J=6.3 \mathrm{~Hz}$, $\mathrm{H}-9), 5.61(1 \mathrm{H}, d d, J=6.2,16.2 \mathrm{~Hz}, \mathrm{H}-6), 5.73(1 \mathrm{H}, d d, J=0.5,16.2 \mathrm{~Hz}, \mathrm{H}-5), 5.83(1 \mathrm{H}, d, J=15.4 \mathrm{~Hz}, \mathrm{H}-2)$, $6.84(1 \mathrm{H}, d, J=15.5 \mathrm{~Hz}, \mathrm{H}-3)$.

${ }^{13} \mathrm{C}-\mathrm{NMR} \delta$ : 13.9 (8-Me),15.6 (12-Me), 17.8 (13-Me), 24.6 (C10), 26.9 (4-Me), 34.2 (C11), 39.0 (C12), 56.9 (7-OMe), 73.0 (C4), 75.5 (C13), 84.8 (C7), 115.3 (C2), 129.1 (C9), 130.6 (C6), 135.9 (C5), 136.5 (C8), 154.8 (C3), $166.3(\mathrm{C} 1)$.

\subsection{Identification of Actinomycete AR10}

Phylogenetic analysis based on $16 \mathrm{~S}$ rDNA sequence and morphological observation was done as follows. Bacterial 16S rRNA genes were PCR-amplified with primers 9F (5'-GAGTTTGATCCTGGCTCAG) and 1510R (5'-GGCTACCTTGTTACGA). The 16S rRNA gene sequences determined were compared with those retrieved from DNA database of APORON DB-BA 11.0 (Techno Suruga Lab., Shizuoka, Japan) and GenBank/EMBL/DDBJ using a BLAST homology search, and phylogenetic tree was constructed to ascertain the phylogenetic position of the actinomycete strain AR10. Phylogenetic trees were generated by the neighbor-joining method. Gene sequencing and phylogenetic analysis were carried out at Techno Suruga Lab., Co., Ltd. (Shizuoka, Japan).

\subsection{Infection Control Assay of Isolated Actinomycete Strain AR10 against R. solani}

Cucumis sativus L. (cucumber) was used for infection control test. Seeds were soaked in $70 \%$ ethanol for 10 sec, sterilized with $1 \% \mathrm{NaClO}$ for $10 \mathrm{~min}$, and finally rinsed three times with sterile distilled water. Sterilized seeds were germinated under dark conditions for 3 days on water agar plate. The germinated seeds were then transferred to agripot containing water agar medium (agar; 0.8\%), with 3 seeds in one pot. AR10 was cultured in PDB medium at $24{ }^{\circ} \mathrm{C}, 1,500 \mathrm{rpm}$ (stirred culture) for 3 days. Mycelia of AR10 were collected by centrifugation and then resuspended by $0.01 \mathrm{~g}$ mycelia/ $100 \mu \mathrm{L}$ of culture broth. Resulting mycelia solution was spread in the agripot just before transplant of germinated seeds. Five days after the transplant, the infection assay was carried out by placing $0.7-\mathrm{cm}$-diameter agar plugs of plant pathogens onto the center of agripots. Biocontrol effect was assessed after the plants were grown in growth chamber for 12 days at $24{ }^{\circ} \mathrm{C}, 12 \mathrm{~h} \mathrm{light/dark}$ condition.

\section{Results and Disscusion}

This study was aimed to evaluate the antagonistic potential of actinomycetes isolated from the soil around the ant nests, and there was a great deal of antagonistic actinomycetes in the soil samples. The antifungal activities of actinomycetes against $R$. solani were investigated using in vitro dual culture assays. Of the fifty strains tested, seventeen strains were found to be moderately effective and five strains showed strong antifungal activities. The five strains were named AR1, AR2, AR3, AR4, AR10, and applied to assay for antifungal activity against eight phytopathogenic fungi. As shown in Table 1, AR10 was most effective in antagonistic suppression against phytopathogenic fungi in the dual culture assay. AR10 showed inhibitory effect on all plant pathogens except $P$. infestans. In particular, AR10 showed inhibitory effect on C. echinochloa and F. oxysporum, which suggested that the presence of antifungal compound(s) different from other actinomycetes.

Table 1. Antifungal activity of actinomycetes against plant pathogens on PDA

\begin{tabular}{|c|c|c|c|c|c|}
\hline \multirow{2}{*}{ Plant pathogens } & \multicolumn{5}{|c|}{ Inhibition zone index* } \\
\hline & AR1 & AR2 & AR3 & AR4 & AR10 \\
\hline Bipolaris oryzae & +++ & +++ & +++ & +++ & +++ \\
\hline Colletotrichum echinochloae & + & + & - & + & ++ \\
\hline Colletotrichum orbiculare & ++ & +++ & +++ & ++ & +++ \\
\hline Fusarium oxysporum & - & - & + & - & + \\
\hline Fusarium solani & ++ & ++ & ++ & ++ & ++ \\
\hline Monilinia fructigena & + & ++ & ++ & ++ & ++ \\
\hline Phytophthora infestans & - & - & + & - & - \\
\hline Rhizoctonia solani & ++ & ++ & ++ & - & + \\
\hline
\end{tabular}

Note. * inhibition zone index;,$-<10 \mathrm{~cm}^{2} ;+, 10-20 \mathrm{~cm}^{2} ;++, 20-30 \mathrm{~cm}^{2} ;+++,>30 \mathrm{~cm}^{2}$.

To extract and detect the antifungal substance from AR10, the extracts of the strain were fractionated by TLC analysis. Bioautography was used to assess the activity of the compounds present in the TLC (Figure 1). 
Antifungal metabolite $(\mathrm{Rf}=0.44)$ was detected on the plate by observation of clear zones where active compounds inhibit fungal growth (Figure 1). The most active band was purified by preparative TLC and HPLC. The HPLC chromatogram of isolated antifungal compounds are shown in Figure 2. Clear single peak was detected at a retention time of 11 minutes, and the compound recovered from this peak was subjected to the antifungal activity test. The compound showed an antifungal activity at $200 \mu \mathrm{g} / \mathrm{disk}$ as shown in Figure 2 . To characterize this compound, the peak sample was subjected to LC-MS and NMR analysis. In LC-MS chromatogram, a peak was detected at a retention time of 24 minutes, which showed a molecular ion $[\mathrm{M}+\mathrm{H}]^{+}$of $m / z 309.5$ (Figure 3). ${ }^{1} \mathrm{H}$ and ${ }^{13} \mathrm{C}$ NMR spectrum of this compound were consistent with that of albocycline which was previonaly reported (Zucchi, Almeida, Moraes, \& Cônsoli, 2014; Harada et al., 1984), and thus, the isolated compound was identified as albocycline.

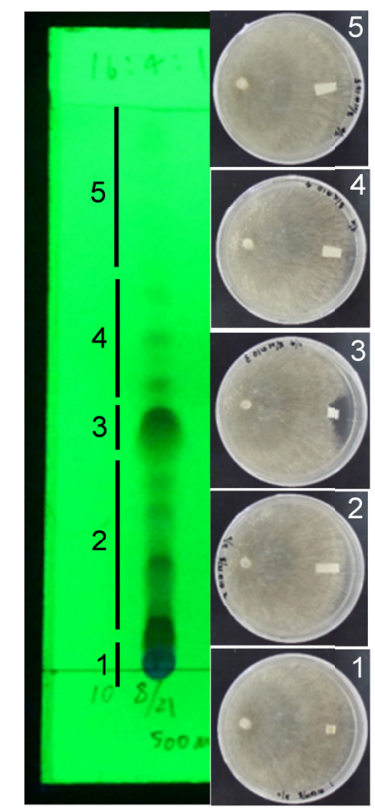

Figure 1. TLC analysis and bioassay from the culture of AR10

Note. The antifungal compounds in the EtOAc extract of strain AR10 were separated using TLC, and antifungal activity was tested by measuring the ability to inhibit fungal growth of $R$. solani on PDA plate. The number (1-5) in the photograph indicates each fraction of preparative TLC.

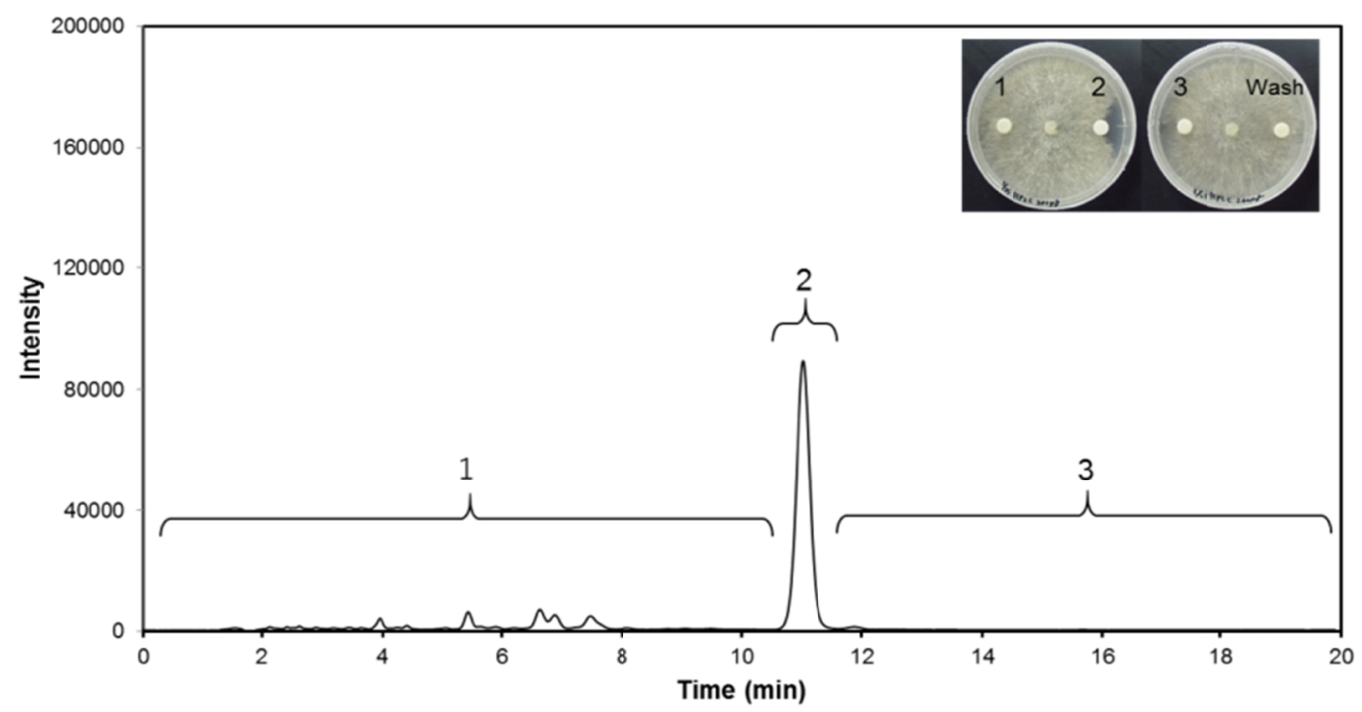

Figure 2. HPLC analysis of partially purified extract of the selected actinomycete strain AR10

Note. Peak 2 is an antifungal compound produced by AR10. 


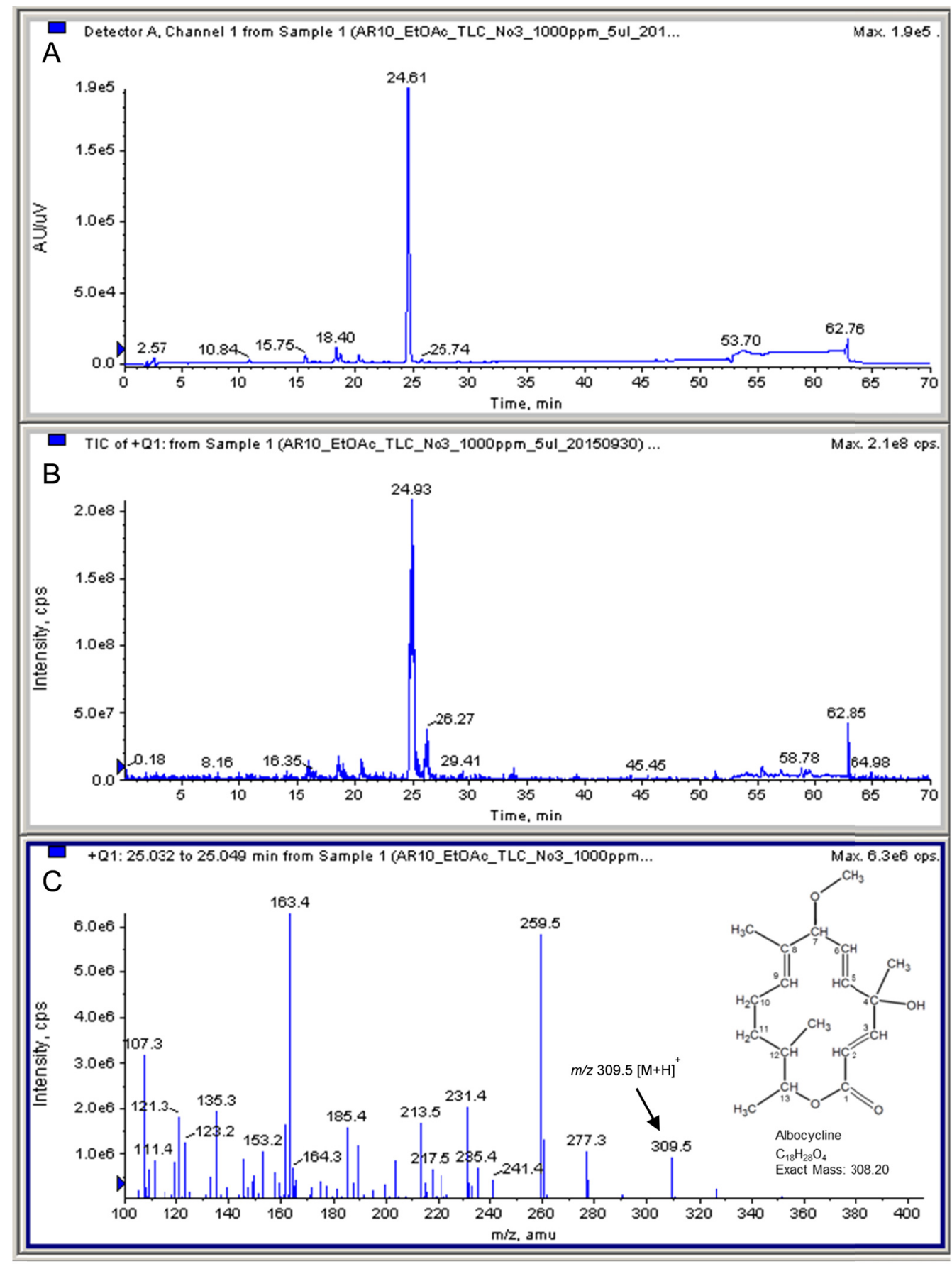

Figure 3. LC-MS profile of peaks at retention time of 25 which is attributed to albocycline

Note. UV spectrum (A), Total ion chromatogram (B), MS spectrum (C).

In order to investigate whether isolated AR10 strain can be used as a biocontrol agent, we performed the infection control assay. As shown in Figure 4, symptom of $R$. solani infection was observed on the 9th day in the control experiment, and the severe damage was observed on the 12th day. But in the pots treated with AR10, infection was not observed as shown in Figure 4, suggesting that AR10 could be a potent biocontrol agent. Similarly, AR1, AR2, AR3 and AR4 were assayed. AR4 could not inhibit the infection of $R$. solani, and AR1, AR2 and AR3 could temporarily inhibit the growth of $R$. solani, but long-term inhibition was not observed (data not shown). On the other hand, AR10 was able to suppresse $R$. solani for about a month. This result suggested that the suppressive effect in dual culture is not necessarily led to the efficacy of infection control of plant 
pathogens. As AR10 has the high inhibitory activity in the agar medium assay, it is hopeful to observe similar effects in the actual field.

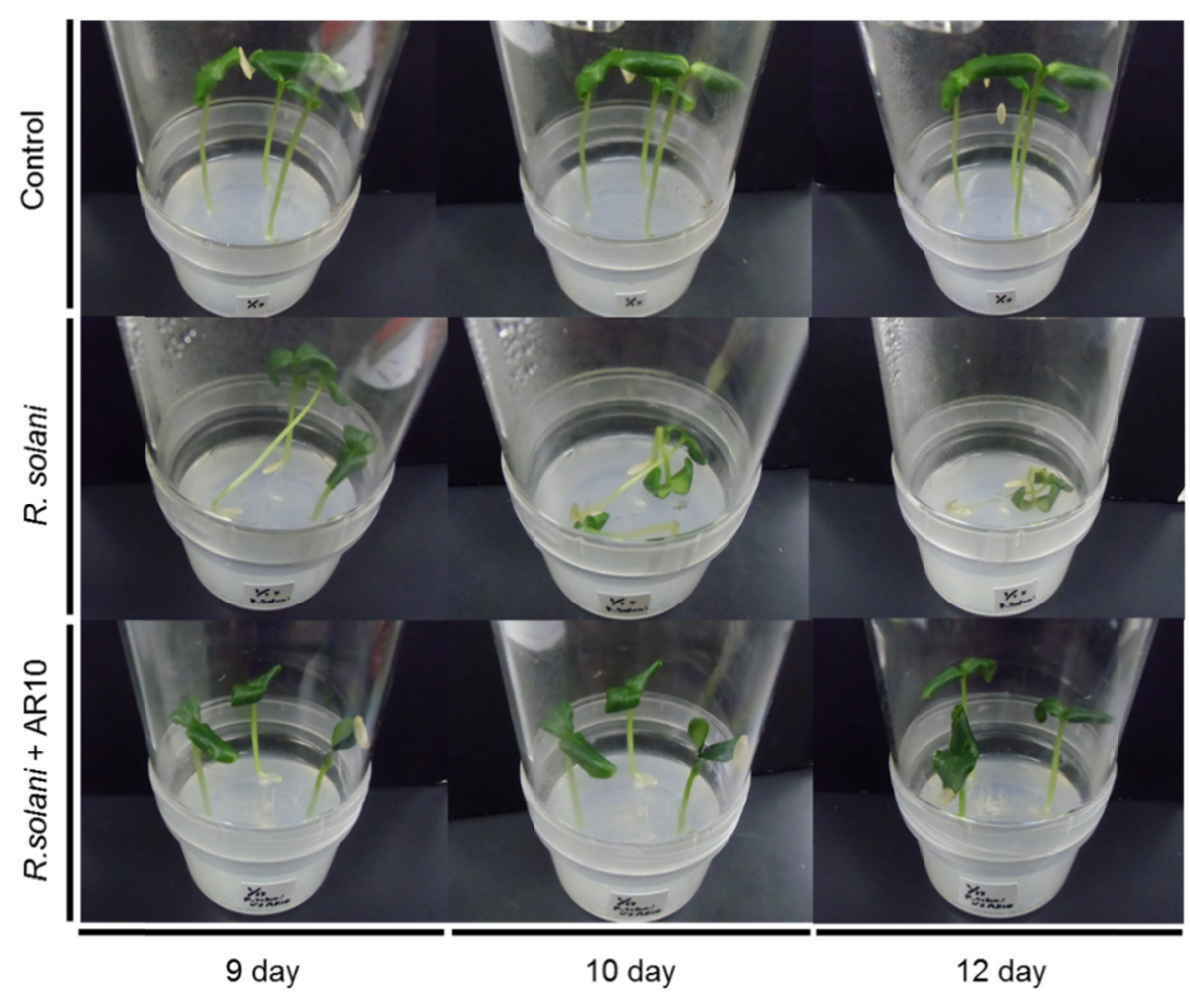

Figure 4. Infection control of strain AR10 against cucumber damping-off ( $R$. solani). Infection control was assessed after the plants were grown in growth chamber for 12 days at $24{ }^{\circ} \mathrm{C}, 12 \mathrm{~h} \mathrm{light} /$ dark condition

In a plate culture of AR10, aerial mycelium was formed, and the surface of the colony had cottony appearance. Microscopic observation of AR10 showed thin filaments, spore chain and it was gram-positive. As a result of 16S rDNA analysis of AR10, it was suggested that it is Streptomyces sp. (Figure 5). In addition, albocycline production by Streptomyces maizeus, S. venezuelae, S. bruneogriseus and other actinomycetes such as Propionicimonas sp. (Slechta, Cialdella, \& Hoeksema, 1978; Zucchi et al., 2014; Harada et al., 1984) have been reported. However, the production of albocycline by Streptomyces closely related to AR 10 in the phylogenetic tree has not been reported. Therefore, AR10 may be a new kind of actinobacteria closely related to these actinomycetes. Most of the actinomycetes are known to produce chitinase (Castillo et al., 2016; Sakdapetsiri et al., 2016), and, in our experiment, the production of chitinase by AR 10 was also detected by the colloidal chitin plate assay (data not shown). The antifungal activity of AR10 was suggested to be improved by the concerted inhibition activities of lytic activity of chitinase and antibiotic activity of albocycline. Indeed, enhancement of antifungal activity by an antimicrobial substance and a lytic enzyme has been observed (Lorito, Peterbauer, Hayes, \& Harman, 1994). Therefore, the cells of this strain itself must be an effective biocontrol agent and more potent than the isolated antibiotic substance. These results may suggest that AR10 can work as a biological agent in the real agricultural field. Moreover, AR10 produced enzymes such as phytase and phosphatase and siderophore (data not shown) as well as chitinase, and it has been reported that these enzymes and compounds are involved in promotion of plant growth (Jog, Nareshkumar, \& Rajkumar, 2012). Therefore, application of AR10 may contribute to both plant growth promotion and pathogen control. 


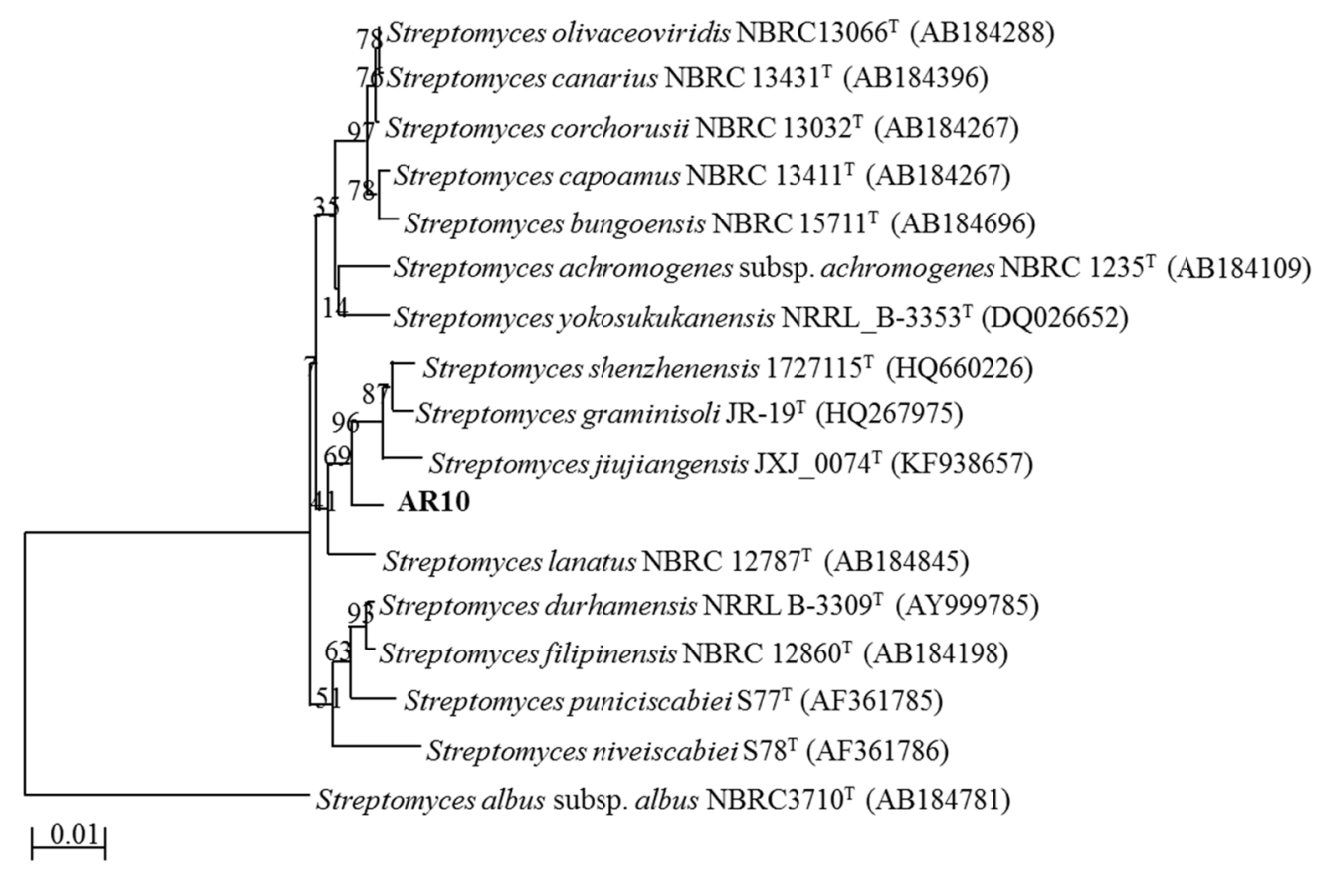

Figure 5. 16S rDNA gene sequences showing relationships between Streptomyces isolates and related Streptomyces type strain species. Numbers at nodes indicate levels of bootstrap support based on a neighbour-joining analysis of 1000 resampled datasets

\section{Conclusion}

We isolated fifty strains of actinomycetes from soil samples and carried out a dual culture assay against $R$. solani. Among them, the AR10 strain had the strongest antifungal activity, and it was able to inhibit eight species of plant pathogens. Actinomycete strain AR10 produced albocycline which is an antifungal compound and was able to suppress Rhizoctonia damping-off. Although this compound is already known, the production of albocycline by Streptomyces closely related to AR10 in the phylogenetic tree has not been reported. Furthermore, AR10 produced not only albocycline but also cell degradation enzymes such as chitinase. Therefore, the production of albocycline and cell degradation enzyme may contribute to inhibition of plant pathogens by its synergistic effect on the antifungal activity of AR10. In Addition, AR10 may be able to promote plant growth by producing enzymes and siderophores related to PGP. From these facts, strain AR10 can be expected as a candidate for biological control agents to suppress plant diseases.

\section{References}

Ando, M. (1991). Pesticide pollution and its risk on human health. Journal of Environmental Chemistry, 1, 16-37. https://doi.org/10.5985/jec.1.16

Brzezinska, M. S., Jankiewicz, U., \& Walczak, M. (2013). Biodegradation of chitinous substances and chitinase production by the soil actinomycete Streptomyces rimosus. International Biodeterioration \& Biodegradation, 84, 104-110. https://doi.org/10.1016/j.ibiod.2012.05.038

Castillo, B. M., Dunn, M. F., Navarro, K. G., Meléndez, F. H., Ortiz, M. H., Guevara, S. E., \& Palacios, G. H. (2016). Antifungal performance of extracellular chitinases and culture supernatants of Streptomyces galilaeus CFFSUR-B12 against Mycosphaerella fijiensis Morelet. World Journal of Microbiology and Biotechnology, 32-44. https://doi.org/10.1007/s11274-015-1993-0

Chellemi, D. O. (2002). Nonchemical management of soilborne pests in fresh market vegetable production systems. Phytopathology, 92, 1362-1372. https://doi.org/10.1094/PHYTO.2002.92.12.1367

Chikh-Rouhou, H., Sta-Baba, R., Ayed, C., Belgacem, S., Boughalleb, B., \& Cherif, M. (2013). Physiological races of Fusarium oxysporum f.sp. melonis in Tunisia. Phytoparasitica, 41, 593-596. https://doi.org/ 10.1007/s12600-013-0321-1

Chuping, L., Xuehui, L., Huafei, Z., Xiaoyu, W., \& Zhiyi, C. (2014). Identification of Four NRPS gene Clusters in Bacillus subtilis 916 for Four Families of Lipopeptides Biosynthesis and Evaluation of Their Intricate 
Functions to the Typical Phenotypic Features. Applied and Environmental Microbiology, 81, $422-431$. https://doi.org/10.1128/AEM.02921-14

Clevo, W., \& Clem, T. (2001). Why farmers continue to use pesticides despite environmental, health and sustainability costs. Ecological Economics, 39(3), 449-462. https://doi.org/10.1016/S0921-8009(01) 00238-5

FAO (Food and Agriculture Organization of the United Nations). (2012). World agriculture towards 2030/2050: The 2012 revision. Agricultural Development Economics Division, Food and Agriculture Organization of the United Nations. Retrieved from http://www.fao.org/home/en

Haeder, S., Wirth, R., Herz, H., \& Spiteller, D. (2009). Candicidin-producing Streptomyces support leaf-cutting ants to protect their fungus garden against the pathogenic fungus Escovopsis. Proceedings of the National Academy of Sciences, 106, 4742-4746. https://doi.org/10.1073/pnas.0812082106

Harada, K., Nishida, F., Takagi, H., Suzuki, M., \& Iwashita, T. (1984). Studies on an antibiotic, albocycline. The Journal of Antibiotics, 37, 1187-1197. https://doi.org/10.7164/antibiotics.37.1187

Jaiswal, A. K., Elad, Y., Graber, E. R., \& Frenkel, O. (2007). Rhizoctonia solani suppression and plant growth promotion in cucumber as affected by biochar pyrolysis temperature, feedstock and concentration. Soil Biology and Biochemistry, 69,110-118. https://doi.org/10.1016/j.soilbio.2013.10.051

Jog, R., Nareshkumar, G., \& Rajkumar, S. (2012). Plant growth promoting potential and soil enzyme production of the most abundant Streptomyces spp. from wheat rhizosphere. Journal of Applied Microbiology, 113, 1154-1164. https://doi.org/10.1111/j.1365-2672.2012.05417.x

Lorito, M., Peterbauer, C., Hayes, C. K., \& Harman, G. E. (1994). Synergistic interaction between fungal cell wall degrading enzymes and different antifungal compounds enhances inhibition of spore germination. Microbiology, 140, 623-629. https://doi.org/10.1099/00221287-140-3-623

Oh, D., Poulsen, M., Currie, C. R., \& Clard, J. (2009). Dentigerumycin: A bacterial mediator of an ant-fungus symbiosis. Nature Chemical Biology, 5, 391-393. https://doi.org/10.1038/nchembio.159

Ploetz, R. C. (2006). Fusarium wilt of banana is caused by several pathogens referred to as Fusarium oxysporum f. sp. Cubense. Phytopathology, 96, 653-656. https://doi.org/10.1094/PHYTO-96-0653

Poulsen, M., Bot, N. A. M., Currie, C. R., Nielsen, M. G., \& Boomsma, J. J. (2003). Within-colony transmission and the cost of a mutualistic bacterium in the leaf-cutting ant Acromyrmex octospinosus. Functional Ecology, 17, 260-269. https://doi.org/10.1046/j.1365-2435.2003.00726.x

Prabavathy, P. R., Mathivanan, N., \& Murugesan, K. (2006). Control of blast and sheath blight diseases of rice using antifungal metabolites produced by Streptomyces sp. PM5. Biological Control, 39, 313-319. https://doi.org/10.1016/j.biocontrol.2006.07.011

Sakdapetsiri, C., Fukuta, Y., Aramsirirujiwet, Y., Shirasaka, N., \& Kitpreechavanich, V. (2016). Antagonistic activity of endo- $\beta$-1,3-glucanase from a novel isolate, Streptomyces sp. $9 \mathrm{X} 166$, against black rot in orchids. Journal of Basic Microbiology, 56(5), 469-479. https://doi.org/10.1002/jobm.201500709

Slechta, L., Cialdella, J., \& Hoeksema, H. (1978). Biomodification of albocycline by Streptomyces venezuelae. The Journal of Antibiotics, 31, 319-323. https://doi.org/10.7164/antibiotics.31.319

Staub, T., \& Sozzi, D. (1984). Fungicide Resistance: A Continuing Challenge. Plant Disease, 68, 1026-1031. https://doi.org/10.1094/PD-68-1026

Wang, C., Wang, Z., Qiao, X., Li, Z., Li, F., Chen, M., ... Cui, H. (2013). Antifungal activity of volatile organic compounds from Streptomyces alboflavus TD-1. FEMS Microbiology Letters, 341, 45-51. https://doi.org/ 10.1111/1574-6968.12088

Zucchi, T. D., Almeida, L. G., Moraes, L. A. B., \& Cônsoli, F. L. (2014). Albocycline, the main bioactive compound from Propionicimonas sp. ENT-18 against Sclerotinia sclerotiorum. Industrial Crops and Products, 52, 264-268. https://doi.org/10.1016/j.indcrop.2013.10.033

\section{Copyrights}

Copyright for this article is retained by the author(s), with first publication rights granted to the journal.

This is an open-access article distributed under the terms and conditions of the Creative Commons Attribution license (http://creativecommons.org/licenses/by/4.0/). 